\title{
Review of: "Excitatory synapses and gap junctions cooperate to improve Pv neuronal burst firing and cortical social cognition in Shank2-mutant mice"
}

\author{
Vassiliki Aroniadou-Anderjaska ${ }^{1}$ \\ 1 Uniformed Services University of the Health Sciences
}

Potential competing interests: The author(s) declared that no potential competing interests exist.

This study by Lee et al. (2021), which has already been published (in Nature Communications), is related to the mechanisms underlying the pathophysiology of autism. Understanding these mechanisms is necessary for the development of effective treatments for this disorder. This paper is not easy to read even for neuroscientists. Here, I will review this paper, not as an expert in the particular field but as a neuroscientist who is very interested in the topic, and I will attempt to use language that can be understood by a broader readership. I will start with a necessary introduction that will place the study into context, and then describe and discuss the main findings.

One of the clinical features of autism is abnormalities in brain oscillatory activity ${ }^{1,2,3,4}$. Brain oscillations reflect synchronized, rhythmic electrical activity of neurons within local neuronal networks and across dispersed networks. The patterns of brain oscillatory activity in relation to behavior and the consequences of their disruption have suggested that brain oscillations facilitate information processing and complex cognitive functions by integrating sensory and perceptual information across neuronal networks $5,6,7$. To begin to understand the causes of alterations in brain oscillations in autism and other neuropsychiatric disorders, we first have to understand the mechanisms that give rise to synchronized, rhythmic neuronal activity. These mechanisms are not well-understood, but it is clear that GABAergic interneurons (neurons which, when active, inhibit the neurons to which they connect, by releasing the neurotransmitter GABA) play an instrumental role $8,9,10,11$. This is significantly due to the ability of interneurons to synchronize their firing ${ }^{12,13,14}$ (strong electrical activity), which allows them to control, reset, and impose a rhythm on the activity of a large cohort of principal (excitatory) neurons ${ }^{12,15}$. A key feature of interneurons that allows them to synchronize their activity is the presence of "gap junctions", through which groups of them are connected; gap junctions allow electrical activity to directly spread from one interneuron to others in the group, resulting in synchronous firing.

Electrical activity of interneurons is initiated by synaptic input from excitatory neurons onto interneurons, which (excitatory input) is mediated for the most part by receptors to the neurotransmitter glutamate. The NMDA receptors (NMDARs) is one type of glutamate receptors; importantly, NMDAR hypofunction is 
another characteristic feature of autism ${ }^{16,17}$. NMDARs play key roles in fundamental processes such as brain development ${ }^{18}$ and synaptic plasticity ${ }^{19,20,21}$ (which appears to be the cellular mechanism underlying learning and memory ${ }^{22}$ ). In recent years, there has been growing interest in the involvement of NMDARs in the generation of oscillatory activity 23,24,25,26. The mechanisms of NMDAR involvement in the generation of oscillations are unclear, however their presence on GABAergic interneurons seems to play a key role; knocking out (removing by genetic manipulation) NMDARs from a specific class of interneurons (those containing the protein parvalbumin), in mice, disrupts normal oscillatory activity 27,28 , and simulated antagonism of NMDARs in a computer model of the hippocampus disrupts oscillations only when antagonism is applied to NMDARs on interneurons ${ }^{29}$. A recent study conducted in our laboratory suggested that in the amygdala-a brain region that has a central role in emotional behavior ${ }^{30}$ and dysfunction of which is involved in a host of neuropsychiatric disorders including autism $31,32,33$ _NMDARs on interneurons play a pivotal role in driving synchronous rhythmic inhibition of principal neurons ${ }^{34}$.

The study by Lee et al. (2021) was conducted in a mouse model of autism spectrum disorders, the Shank2mutant (Shank $2^{-1-}$ ) mice ${ }^{35}$. Shank2 is a synaptic protein that interacts directly or indirectly with receptors of the postsynaptic membrane, including NMDARs, and with other elements that shape the structure of a synapse $^{36}$. Mutations in the human SHANK2 gene have been associated with autism and related disabilities ${ }^{37}$. Shank2 $2^{-/-}$mice exhibit autistic-like behaviors, show a marked decrease in NMDAR function, and experimentally normalizing NMDAR function improves behavior ${ }^{35}$.

The main findings described in the first part of the Lee et al. (2021) paper could be summarized as follows: 1) In comparison with the wild-type (WT) mice (normal/non-genetically altered mice), Shank $2^{-/-}$mice had a higher proportion of neurons in the medial prefrontal cortex (MPFC, a brain region that is central to cognitive functions) that fired when the mice were exposed to non-social targets (as opposed to a social target, i.e., another mouse). 2) Interneurons in the MPFC of the WT mice displayed a higher proportion of firing at high frequencies ("burst firing") when exposed to a target than in the resting state; in contrast, interneurons in the Shank2-/- mice displayed more high-frequency burst firing in the resting state. 3) The change in burst firing of interneurons in the WT mice relative to the resting state was significantly greater upon encountering a social target than upon encountering non-social targets; such differences were absent in the Shank2-l- mice. 4) The change in burst firing upon exposure to a social target in relation to rest was significantly greater in the WT than in the Shank2-/- mice, which failed to increase their burst firing upon social target exposure. Such differences between the two groups were not seen in the firing characteristics of principal neurons, which elevated their firing rates upon exposure to a target. [Considering that inhibitory interneurons can be expected to influence the activity of principal neurons, it is somewhat surprising that the abnormalities in high-frequency burst firing of interneurons in the Shank $2^{-/-}$mice did not affect the firing of excitatory neurons.] 
Next, the investigators studied local network oscillations in the MPFC. Compared with the WT mice, the Shank2-/- mice displayed higher total power of local network oscillations in the resting state, at all frequencies, which decreased markedly upon encountering a target. In the WT mice, there were no targetinduced decreases in oscillatory powers, except for a moderate decrease in the theta range. [Thus, so far we see that Shank2 $2^{-/-}$mice display more interneuronal burst firing and higher total oscillatory power in the resting state; upon encountering a target, burst firing of interneurons does not change significantly, while oscillatory power decreases. Does this suggest that there is not necessarily a correspondence between the two?]

Experiments in in vitro slices of the MPFC revealed that spontaneous (basal/unstimulated) inhibitory and excitatory activity recorded from parvalbumin (Pv)-containing interneurons or principal neurons, as well as the overall neuronal excitability did not differ between Shank2-/- mice and WT mice. However, when the PV-interneurons were experimentally stimulated, principal neurons were inhibited effectively in the WT mice, but not in the Shank $2^{-/-}$mice. This result was not possible to explain by a weaker firing of PVinterneurons in the Shank2 $2^{-1-}$ mice in response to stimulation; in fact, both in vitro and in vivo stimulation of Pv-interneurons revealed stronger burst firing in the Shank $2^{-/-}$mice, although the mean firing rate did not differ from that in the WT mice. [Thus, Pv-interneurons in the Shank2-/- mice are more capable of generating burst firing when stimulated, yet they are less effective in inhibiting principal neurons, raising the question of what the underlying mechanisms of this apparent contradiction might be.]

When single Pv-interneurons were stimulated, neighboring interneurons were also activated and generated bursts, significantly more so in the Shank $2^{-/-}$mice. The authors demonstrated that this was due to greater electrical coupling-via gap junctions-between interneurons in the Shank $2^{-/-}$mice. Therefore, stronger connections through gap junctions between Shank $2^{-/-} \mathrm{PV}$-interneurons can explain their stronger bust firing upon stimulation.

Next, the investigators examined whether in Shank2-/- mice, NMDAR activity was impaired in Pvinterneurons in the MPFC. The ratio of NMDAR- over AMPA receptor-mediated EPSCs evoked in PVinterneurons was found to be significantly smaller in Shank2-/- mice compared with that in the WT mice, suggesting NMDAR deficiency in Shank2 ${ }^{-/-}$PV-interneurons. In both WT and Shank2-/- mice, pharmacological activation of NMDARs increased burst firing of PV-interneurons neighboring the stimulated interneuron, and this increase did not occur when the activity of gap junctions was pharmacologically blocked. Thus, in both WT and Shank2-/- mice, facilitation of NMDAR activity increases burst firing of PVinterneurons with the aid of gap junctions by which groups of interneurons are connected.

The next question the study sought to answer was whether increasing burst firing of Pv-interneurons affects social interaction. Stimulation of Pv-interneurons in Shank2 $2^{-/-}$mice so as to boost burst firing 
improved social interaction. However, in another set of experiments involving again stimulation-induced burst firing of Pv-interneurons, the spike-wave synchrony (the synchrony between interneuronal firings and particular phases in the waveform of the local field potentials; such synchrony facilitates cognitive functions ${ }^{38,39}$ ) was decreased in the Shank $2^{-/-}$mice, while it was moderately increased in the WT mice). Furthermore, when gap-junction activity was inhibited in Pv-interneurons of the MPFC in WT mice, there was a moderate but statistically significant increase in social interaction, suggesting that gap junctional activity of Pv-interneurons can have a negative effect on social interaction. Thus, increased burst firing of Pv-interneurons improves social interaction but decreases spike-wave synchrony in the Shank2/- mice, while in WT mice, when gap junction activity is blocked, social interaction increases.

The way the authors suggested that these data could be interpreted is as follows: Gap junctions between interneurons are extensive early in postnatal brain development and decrease as the brain matures ${ }^{40}$. The NMDARs play a role in this reduction ${ }^{41}$. NMDAR hypofunction in Shank2 $2^{-1-}$ mice 35 impairs the role of NMDARs in decreasing gap junctions and/or triggers a compensatory hyperactivity of gap junctions as they try to maintain the output functions of Pv-interneurons. Extensive gap junctions and their hyperactivity in Shank2-l- Pv-interneurons can impair social interaction (supported by the increased social interaction when gap junctions were inhibited in the WT mice; this experiment of blocking specifically PV-interneuronal gap junctions was not technically possible in the Shank $2^{-/-}$mice). Thus, it's possible that the neuronal network synchrony in Shank2 $2^{-/}$mice is too high due to gap junctional hyperactivity, which impairs social interaction. [This speculation necessarily suggests that the stimulation-induced boosting of burst firing of Shank2-/- Pv-interneurons did not make the gap junctions even more hyperactive, but instead suppressed their activity and the excessive network synchrony, thereby promoting social interaction. However, is there any evidence that the stimulation $(10 \mathrm{~Hz})$ the investigators used to boost burst firing of Pv-interneurons disengages rather than recruits even more gap junctions? Weren't the stronger bursts induced by stimulation $(10 \mathrm{~Hz})$ in Shank2 $2^{-/-}$mice, in vitro and in vivo, attributed to the increased activity of gap junctions? Also, doesn't NMDAR activation have a similar effect to that of $10 \mathrm{~Hz}$ stimulation in boosting burst firing, doing so by enhancing gap junction activity, and yet, enhancement of NMDAR activity improves, does not impair, social interaction? Would we expect NMDAR activation to suppress hypersynchrony and, if yes, by what mechanism?]

This paper describes a vast amount of work, thoughtfully designed to probe into the pathophysiology of autism, with the use of state-of-the-art experimental techniques. In a mouse model of autism, NMDARmediated activity was found to be impaired in Pv-interneurons, which play a central role in the oscillatory activity of neuronal networks. In addition, the investigators demonstrated the importance of Pvinterneuronal burst firing in social cognition, and the role of NMDARs and gap junctions in Pv-interneuronal burst firing. I find some of the data difficult to reconcile, but reporting them is important, and a good interpretation may be found in the future. Specifically, since there appears to be hyperactivity of gap 
junctions in the Shank2-/- mice, which may play an important role in impaired social interaction, why stimulation- or NMDAR-induced burst firing of Pv-interneurons, which increase gap junction activity, improve social interaction?

In regard to the role of NMDARs in burst firing of inhibitory interneurons, it is important to determine which subtype of NMDARs is involved; NMDARs containing the GluN2A subunit (GluN2A-NMDARs) and those containing the GluN2B (GluN2B-NMDARs) appear to have both shared and different- and sometimes opposing functions $42,43,44,45$. In the basolateral amygdala, we found that the rhythmic inhibitory activity (spontaneous IPSC "bursts") recorded from principal neurons is driven by burst firing of interneurons via activation of both GluN2A- and GluN2B-NMDARs, but with the GluN2A-NMDARs having a dominant functional presence on interneurons and playing a significantly more prominent role in the burst firing of interneurons ${ }^{34}$. GluN2A-NMDARs have a more pronounced presence than GluN2B-NMDARs also on interneurons of the mouse lateral amygdala ${ }^{46}$ and on cortical PV-interneurons ${ }^{47}$, and there is evidence for a greater role of interneuronal GluN2A-NMDARs in oscillatory activity ${ }^{48}$. In addition, in an animal model of autism, the GluN2A subunit is reduced in the amygdala ${ }^{49}$, and enhancement of GluN2A improves brain oscillations, synchrony, and cognitive functions in animal models of certain diseases where brain oscillations are abnormal ${ }^{50}$. Thus, the development of specific agonists or positive modulators of GluN2ANMDARs $^{51,52,53}$ may potentially find application in the treatment of autism ${ }^{54}$.

Vassiliki Aroniadou-Anderjaska, Ph.D.

Dept. of APG and Psychiatry

F. Edward Hébert School of Medicine

USUHS

4301 Jones Bridge Road,

Bethesda, MD 20814

Vassiliki.aroniadou.anderjaska@gmail.com

References

1. Brock \, Brown CC, Boucher J, Rippon G (2002) The temporal binding deficit hypothesis of autism. Dev Psychopathol 14:209-224.

2. Lai MC, Lombardo MV, Chakrabarti B, Sadek SA, Pasco G, Wheelwright SJ, Bullmore ET, Baron-Cohen S; MRC AIMS Consortium., Suckling J (2010) A shift to randomness of brain oscillations in people with autism. Biol Psychiatry 68:1092-1099. 
3. Cornew L, Roberts TP, Blaskey L, Edgar JC. Resting-state oscillatory activity in autism spectrum disorders. J Autism Dev Disord. 2012 Sep;42(9):1884-94. doi: 10.1007/s10803-011-1431-6.

4. Simon DM, Wallace MT. Dysfunction of sensory oscillations in Autism Spectrum Disorder. Neurosci Biobehav Rev. 2016 Sep;68:848-861. doi: 10.1016/j.neubiorev.2016.07.016.

5. Engel AK, Singer W (2001) Temporal binding and the neural correlates of sensory awareness. Trends Cogn Sci 5:16-25.

6. Bauer EP, Paz R, Paré D (2007) Gamma oscillations coordinate amygdalo-rhinal interactions during learning. Ц Neurosci 27:9369-9379.

7. HansImayr S, Staresina BP, Bowman H (2016) Oscillations and Episodic Memory: Addressing the Synchronization/Desynchronization Conundrum. Trends Neurosci 39:16-25.

8. Bartos M, Vida I, Jonas P (2007) Synaptic mechanisms of synchronized gamma oscillations in inhibitory interneuron networks. Nat Rev Neurosci 8:45-56.

9. Allen K, Monyer H (2015) Interneuron control of hippocampal oscillations. Curr Opin Neurobiol 31:81-87.

10. Sohal VS, Zhang F, Yizhar O, Deisseroth K (2009) Parvalbumin neurons and gamma rhythms enhance cortical circuit performance. Nature 459:698-702.

11. Stark E, Eichler R, Roux L, Fujisawa S, Rotstein HG, Buzsáki G (2013) Inhibition-induced theta resonance in cortical circuits. Neuron 80:1263-1276.

12. Thomson AM (2000) Neurotransmission Chemical and electrical interneuron coupling. Curr Biol 10:R110-112.

13. Muller JF, Mascagni F, McDonald AJ (2005) Coupled networks of parvalbumin-immunoreactive interneurons in the rat basolateral amygdala. J Neurosci 25:7366 -7376.

14. Woodruff AR, Sah P (2007) Networks of parvalbumin-positive interneurons in the basolateral amygdala. J Neurosci 27:553-563.

15. Woodruff AR, Sah P (2007) Inhibition and synchronization of basal amygdala principal neuron spiking 
by parvalbumin-positive interneurons. J Neurophysiol 98:2956-2961.

16. Gandal MJ, Anderson RL, Billingslea EN, Carlson GC, Roberts TP, Siegel SJ (2012) Mice with reduced NMDA receptor expression: more consistent with autism than schizophrenia? Genes Brain Behav 11:740750.

17. Lee El, Choi SY, Kim E (2015) NMDA receptor dysfunction in autism spectrum disorders. Curr Opin Pharmacol 20:8-13.

18. Cull-Candy S, Brickley S, Farrant M (2001) NMDA receptor subunits: diversity, development and disease. Curr Opin Neurobiol 11:327-335.

19. Aroniadou VA, Teyler TJ. The role of NMDA receptors in long-term potentiation (LTP) and depression (LTD) in rat visual cortex. Brain Res. 1991 Oct 18;562(1):136-43. doi: 10.1016/0006-8993(91)91197-9.

20. Malenka RC, Bear MF (2004) LTP and LTD: an embarrassment of riches. Neuron 44:5-21.

21. Morris RG (2013) NMDA receptors and memory encoding. Neuropharmacology 74:32-40.

22. Teyler TJ, Discenna P. Long-term potentiation as a candidate mnemonic device. Brain Res. 1984 Mar;319(1):15-28. doi: 10.1016/0165-0173(84)90027-4.

23. Cadonic C, Albensi BC (2014) Oscillations and NMDA Receptors: Their Interplay Create Memories AIMS Neuroscience 1:52-64.

24. Hakami T, Jones NC, Tolmacheva EA, Gaudias J, Chaumont J, Salzberg M, O'Brien TJ, Pinault D (2009) NMDA receptor hypofunction leads to generalized and persistent aberrant gamma oscillations independent of hyperlocomotion and the state of consciousness. PLoS One. 4: e6755.

25. Hunt MJ, Kasicki S (2013) A systematic review of the effects of NMDA receptor antagonists on oscillatory activity recorded in vivo. J Psychopharmacol 27:972-986.

26. Lazarewicz MT, Ehrlichman RS, Maxwell CR, Gandal MJ, Finkel LH, Siegel SJ (2010) Ketamine modulates theta and gamma oscillations. J Cogn Neurosci 22:1452-1464.

27. Korotkova T, Fuchs EC, Ponomarenko A, von Engelhardt J, Monyer H (2010) NMDA receptor ablation on parvalbumin-positive interneurons impairs hippocampal synchrony, spatial representations, and working 
memory. Neuron 68:557-569.

28. Carlén M, Meletis K, Siegle JH, Cardin JA, Futai K, Vierling-Claassen D, RühImann C, Jones SR, Deisseroth K, Sheng M, Moore Cl, Tsai LH (2012) A critical role for NMDA receptors in parvalbumin interneurons for gamma rhythm induction and behavior. Mol Psychiatry 17:537-48.

29. Neymotin SA, Lazarewicz MT, Sherif M, Contreras D, Finkel LH, Lytton WW (2011) Ketamine disrupts $\theta$ modulation of $\gamma$ in a computer model of hippocampus. J Neurosci 31:11733-11743.

30. Phelps EA, LeDoux JE (2005) Contributions of the amygdala to emotion processing: from animal models to human behavior. Neuron 48:175-187.

31. Schultz RT (2005) Developmental deficits in social perception in autism: the role of the amygdala and fusiform face area. Int J Dev Neurosci 23:125-141.

32. Zalla T, Sperduti M (2013) The amygdala and the relevance detection theory of autism: an evolutionary perspective. Front Hum Neurosci 7:894.

33. Gibbard CR, Ren J, Skuse DH, Clayden JD, Clark CA. (2018) Structural connectivity of the amygdala in young adults with autism spectrum disorder. Hum Brain Mapp. 39:1270-1282. doi: 10.1002/hbm.23915.

34. Aroniadou-Anderjaska V, Pidoplichko VI, Figueiredo TH, Braga MFM. Oscillatory Synchronous Inhibition in the Basolateral Amygdala and its Primary Dependence on NR2A-containing NMDA Receptors. Neuroscience. 2018 Mar 1;373:145-158. doi: 10.1016/j.neuroscience.2018.01.021.

35. Won, H., Lee, HR., Gee, H. et al. Autistic-like social behaviour in Shank2-mutant mice improved by restoring NMDA receptor function. Nature 486, 261-265 (2012). https://doi.org/10.1038/nature11208

36. Boeckers TM, Bockmann J, Kreutz MR, Gundelfinger ED. ProSAP/Shank proteins - a family of higher order organizing molecules of the postsynaptic density with an emerging role in human neurological disease. J Neurochem. 2002 Jun;81(5):903-10. doi: 10.1046/j.1471-4159.2002.00931.x.

37. Berkel S, Marshall CR, Weiss B, Howe J, Roeth R, Moog U, Endris V, Roberts W, Szatmari P, Pinto D, Bonin M, Riess A, Engels H, Sprengel R, Scherer SW, Rappold GA. Mutations in the SHANK2 synaptic scaffolding gene in autism spectrum disorder and mental retardation. Nat Genet. 2010 Jun;42(6):489-91. doi: $10.1038 / n g .589$. 
38. Lee H, Dvorak D, Fenton AA. Targeting Neural Synchrony Deficits is Sufficient to Improve Cognition in a Schizophrenia-Related Neurodevelopmental Model. Front Psychiatry. 2014 Feb 14;5:15. doi:

10.3389/fpsyt.2014.00015.

39. Uhlhaas PJ, Pipa G, Lima B, Melloni L, Neuenschwander S, Nikolić D, Singer W. Neural synchrony in cortical networks: history, concept and current status. Front Integr Neurosci. 2009 Jul 30;3:17. doi: 10.3389/neuro.07.017.2009.

40. Belousov AB, Fontes JD. Neuronal gap junctions: making and breaking connections during development and injury. Trends Neurosci. 2013 Apr;36(4):227-36. doi: 10.1016/j.tins.2012.11.001.

41. Arumugam, H., Liu, X., Colombo, P. J., Corriveau, R. A. \& Belousov, A. B. NMDA receptors regulate developmental gap junction uncoupling via CREB signaling. Nat. Neurosci. 8, 1720-1726 (2005).

42. Lujan B, Liu X, Wan Q. Differential roles of GluN2A- and GluN2B-containing NMDA receptors in neuronal survival and death. Int J Physiol Pathophysiol Pharmacol. 2012;4(4):211-8. Epub 2012 Dec 26. PMID: 23320134; PMCID: PMC3544217.

43. Radiske, A., Gonzalez, M.C., Nôga, D.A. et al. GluN2B and GluN2A-containing NMDAR are differentially involved in extinction memory destabilization and restabilization during reconsolidation. Sci Rep 11, 186 (2021). https://doi.org/10.1038/s41598-020-80674-7

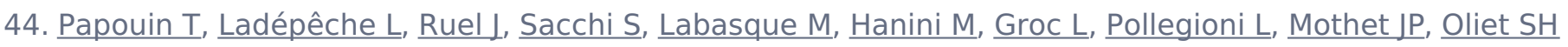
(2012) Synaptic and extrasynaptic NMDA receptors are gated by different endogenous coagonists. Cell 150:633-646.

45. Zhang XM, Luo JH. GluN2A versus GluN2B: twins, but quite different. Neurosci Bull. 2013 Dec;29(6):761-72. doi: 10.1007/s12264-013-1336-9. Epub 2013 Apr 20. PMID: 23604599; PMCID: PMC5561830.

46. Polepalli JS, Sullivan RK, Yanagawa Y, Sah P (2010) A specific class of interneuron mediates inhibitory plasticity in the lateral amygdala. $\perp$ Neurosci 30:14619-14629.

47. Kinney JW, Davis CN, Tabarean I, Conti B, Bartfai T, Behrens MM (2006) A specific role for GLUN2Acontaining NMDA receptors in the maintenance of parvalbumin and GAD67 immunoreactivity in cultured interneurons. J Neurosci 26:1604-1615 
48. Kocsis B (2012) Differential role of NR2A and NR2B subunits in N-methyl-D-aspartate receptor antagonist-induced aberrant cortical gamma oscillations. Biol Psychiatry 71:987-995.

49. Schoch H et al. (2017): Sociability Deficits and Altered Amygdala Circuits in Mice Lacking Pcdh10, an Autism Associated Gene. Biol Psychiatry 81:193-202.

50. Hanson JE, Ma K, Elstrott J, Weber M, Saillet S, Khan AS, Simms J, Liu B, Kim TA, Yu GQ, Chen Y, Wang TM, Jiang Z, Liederer BM, Deshmukh G, Solanoy H, Chan C, Sellers BD, Volgraf M, Schwarz JB, Hackos DH, Weimer RM, Sheng M, Gill TM, Scearce-Levie K, Palop JJ. GluN2A NMDA Receptor Enhancement Improves Brain Oscillations, Synchrony, and Cognitive Functions in Dravet Syndrome and Alzheimer's Disease Models. Cell Rep. 2020 30(2):381-396.e4. doi: 10.1016/j.celrep.2019.12.030.

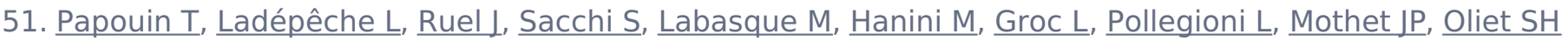
(2012) Synaptic and extrasynaptic NMDA receptors are gated by different endogenous coagonists. Cell 150:633-646.

52. Collingridge GL, Volianskis A, Bannister N, France G, Hanna L, Mercier M, Tidball P, Fang G, Irvine MW, Costa BM, Monaghan DT, Bortolotto ZA, Molnár E, Lodge D, Jane DE (2013) The NMDA receptor as a target for cognitive enhancement. Neuropharmacology 64:13-26.

53. Hackos DH, Lupardus PJ, Grand T, Chen Y, Wang TM, Reynen P, Gustafson A, Wallweber HJ, Volgraf M, Sellers BD, Schwarz JB, Paoletti P, Sheng M, Zhou Q, Hanson JE (2016) Positive Allosteric Modulators of GluN2A-Containing NMDARs with Distinct Modes of Action and Impacts on Circuit Function. Neuron 89:983999.

54. Burket JA, Deutsch SI. Metabotropic functions of the NMDA receptor and an evolving rationale for exploring NR2A-selective positive allosteric modulators for the treatment of autism spectrum disorder. Prog Neuropsychopharmacol Biol Psychiatry. 2019 Mar 2;90:142-160. doi: 10.1016/j.pnpbp.2018.11.017. 